\title{
pH-Responsive Nanofibers for Precise and Sequential Delivery of Multiple Payloads
}

Man Theerasilp and Daniel Crespy*

Department of Materials Science and Engineering, School of Molecular Science and Engineering, Vidyasirimedhi Institute of Science and Technology (VISTEC), Rayong 21210, Thailand

Email: daniel.crespy@,vistec.ac.th 
(a)

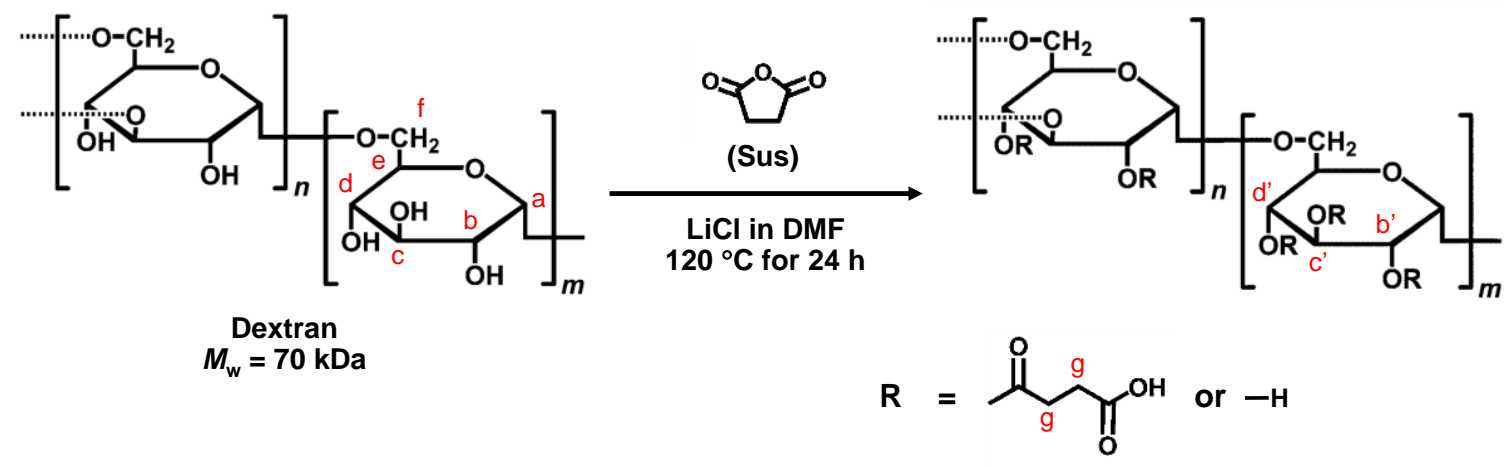

(b)

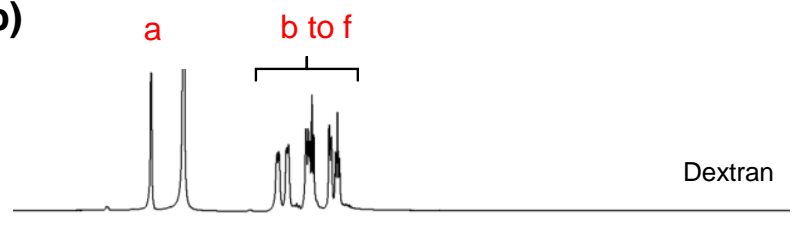

(c)

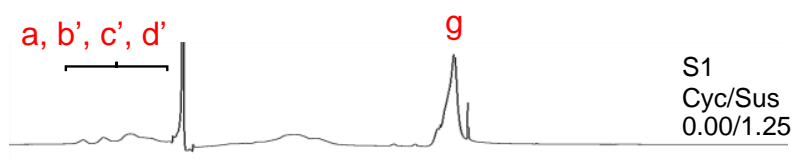

(d)

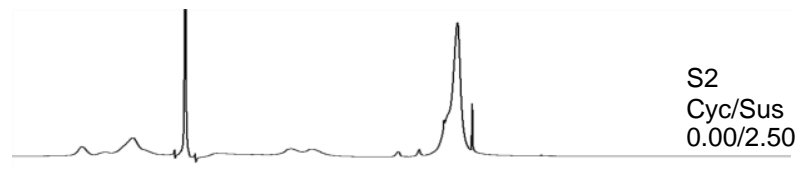

(e)

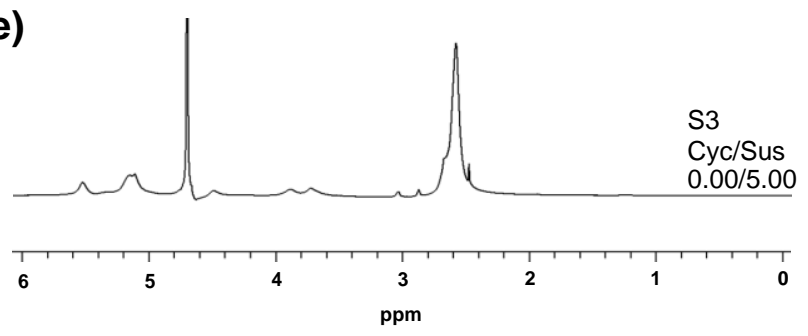

Figure S1. (a) Scheme for the synthesis of Sus-dextran, (b) ${ }^{1}$ H-NMR spectra of dextran and (c to e) ${ }^{1} \mathrm{H}-\mathrm{NMR}$ spectra of Sus-dextran in a solution of $0.75 \mathrm{wt} \% \mathrm{~K}_{2} \mathrm{CO}_{3}$ in $\mathrm{D}_{2} \mathrm{O}$. 
(a)

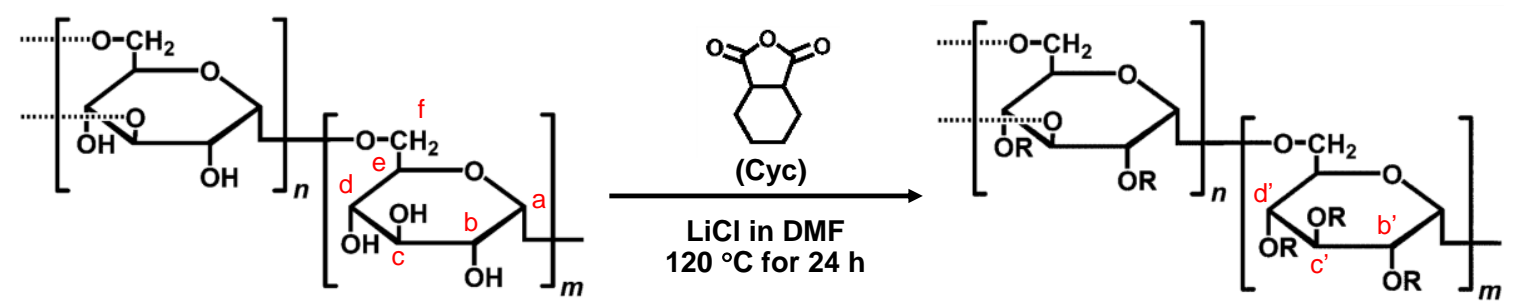
Dextran
$M_{\mathrm{w}}=70 \mathrm{kDa}$

(b)
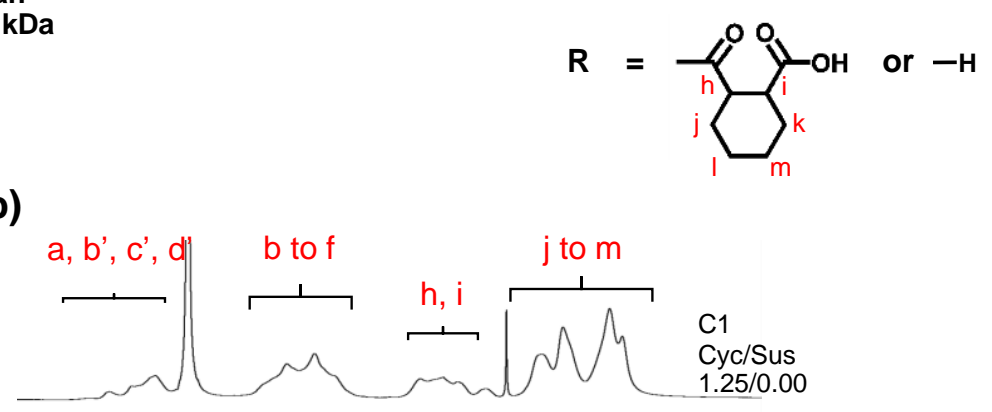

(c)

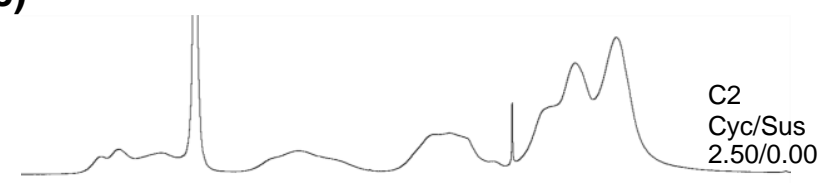

(d)

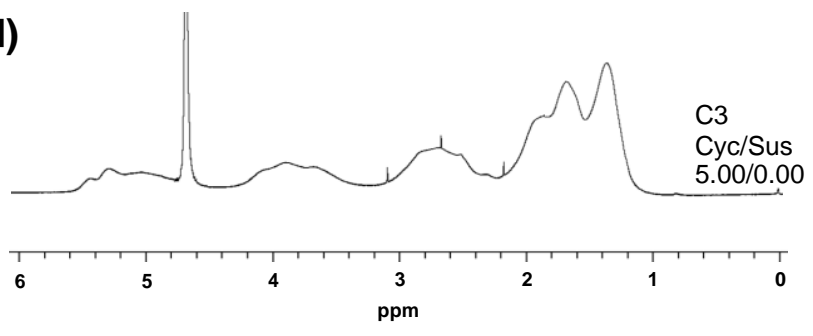

Figure S2. (a) Scheme for the synthesis of Cyc-dextrans and (b to d) ${ }^{1} \mathrm{H}-\mathrm{NMR}$ spectra of Cycdextran in a solution of $0.75 \mathrm{wt} \% \mathrm{~K}_{2} \mathrm{CO}_{3}$ in $\mathrm{D}_{2} \mathrm{O}$. 
(a)
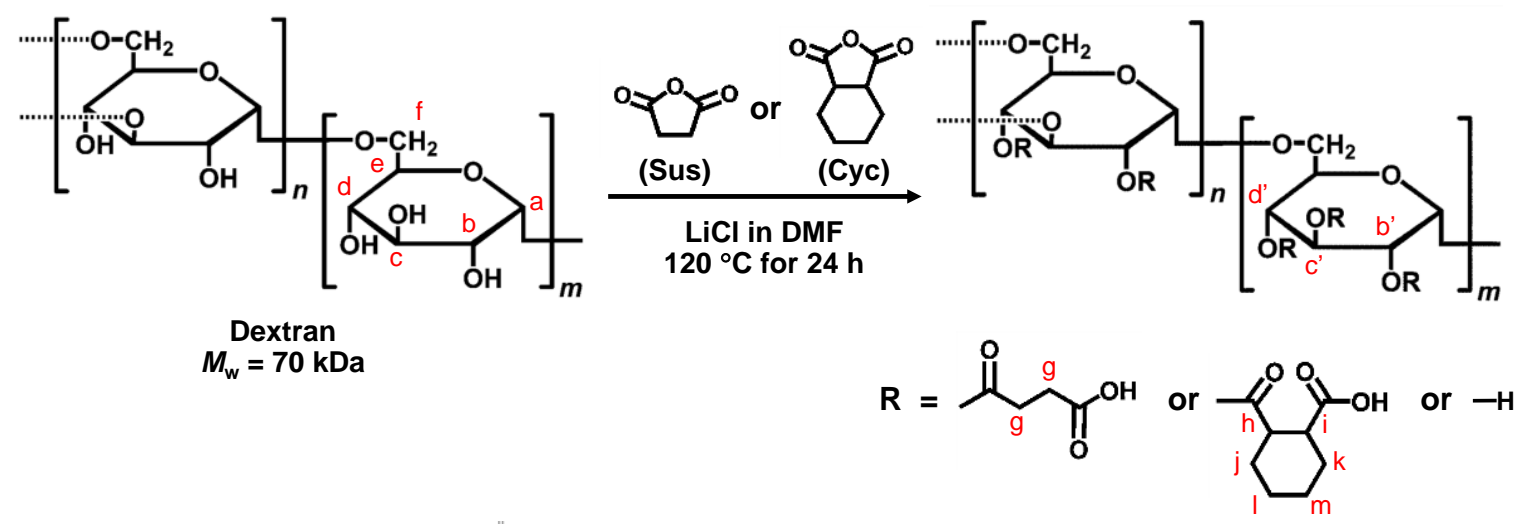

(b)

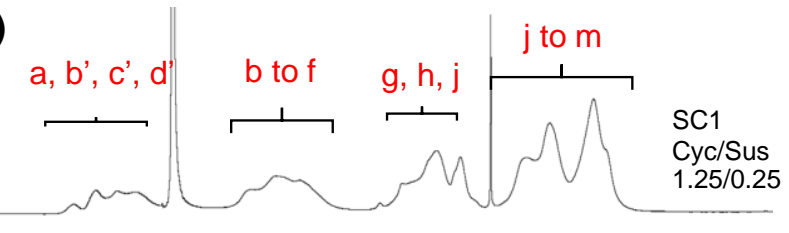

(c)

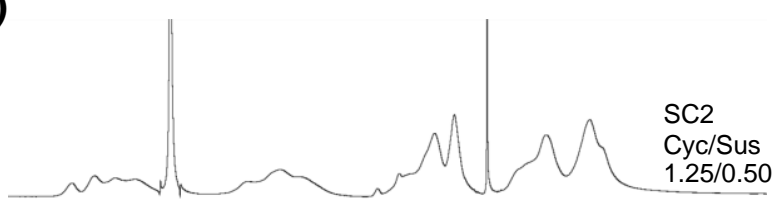

(d)

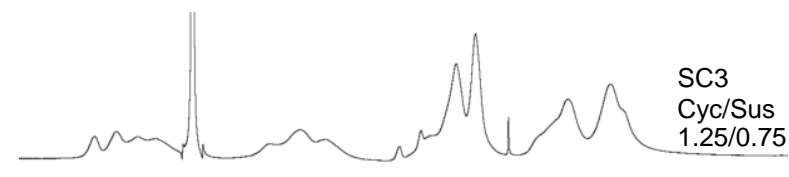

(e)

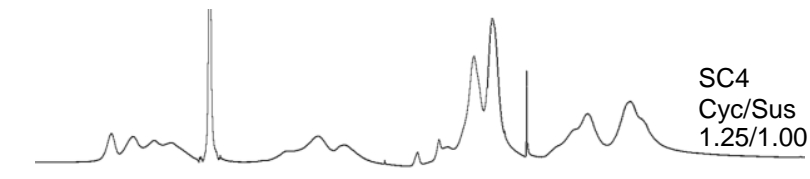

(f)

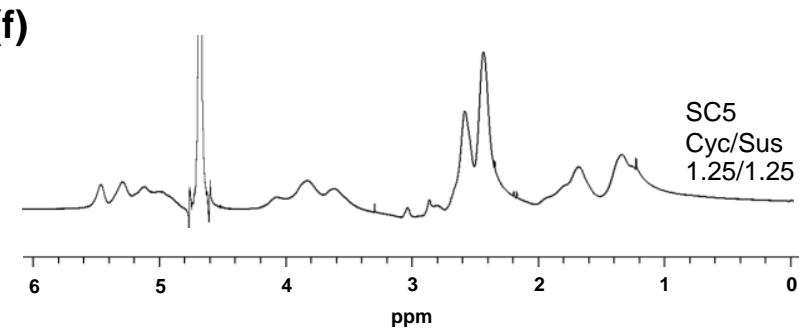

Figure S3. (a) Scheme for the synthesis of Cyc-dextrans and (b to f) ${ }^{1} \mathrm{H}-\mathrm{NMR}$ spectra of Cycdextran in a solution of $0.75 \mathrm{wt} \% \mathrm{~K}_{2} \mathrm{CO}_{3}$ in $\mathrm{D}_{2} \mathrm{O}$. 


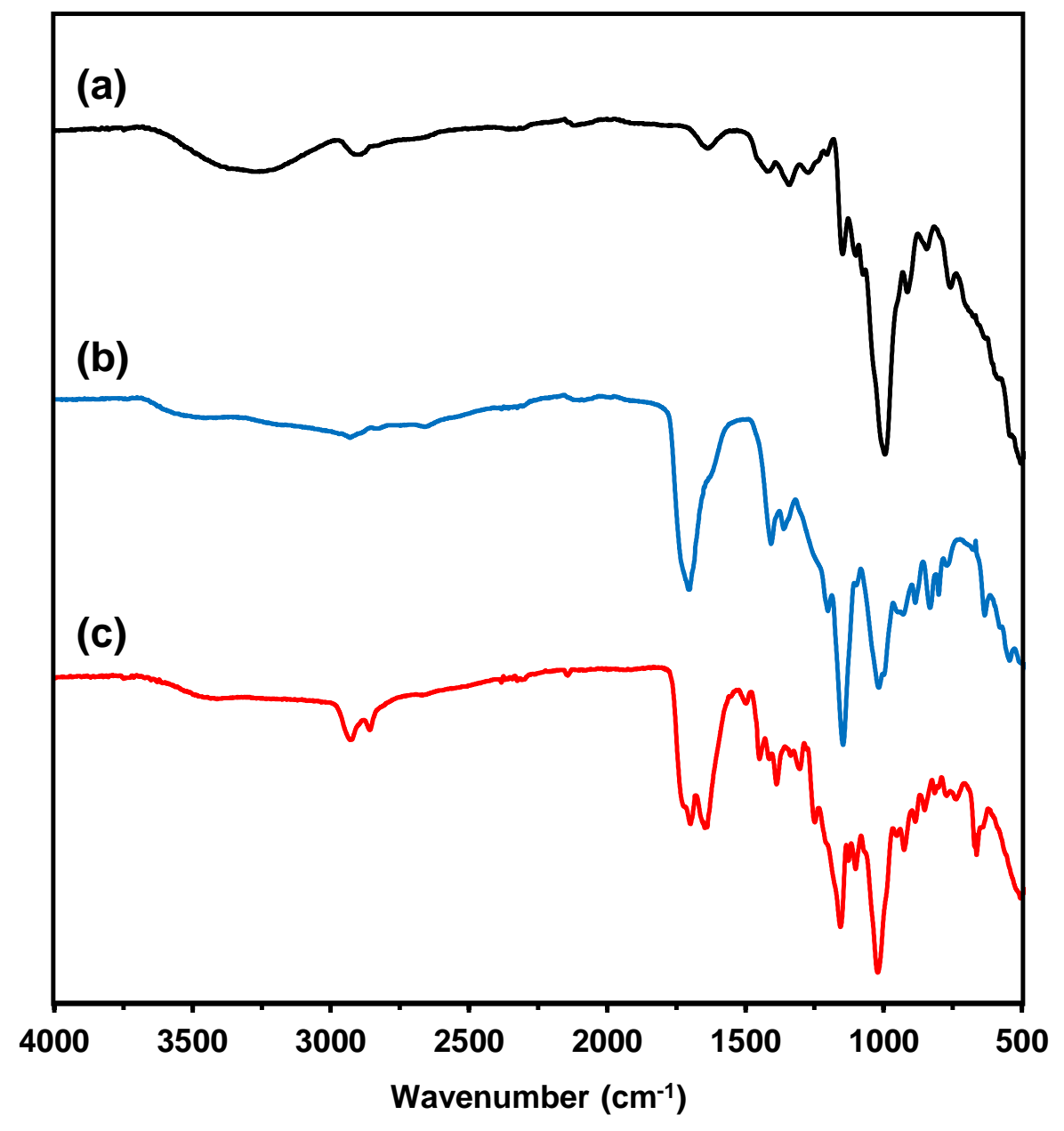

Figure S4. FT-IR spectra of (a) dextran, and (b) S1 and (c) C1 dextran esters. 

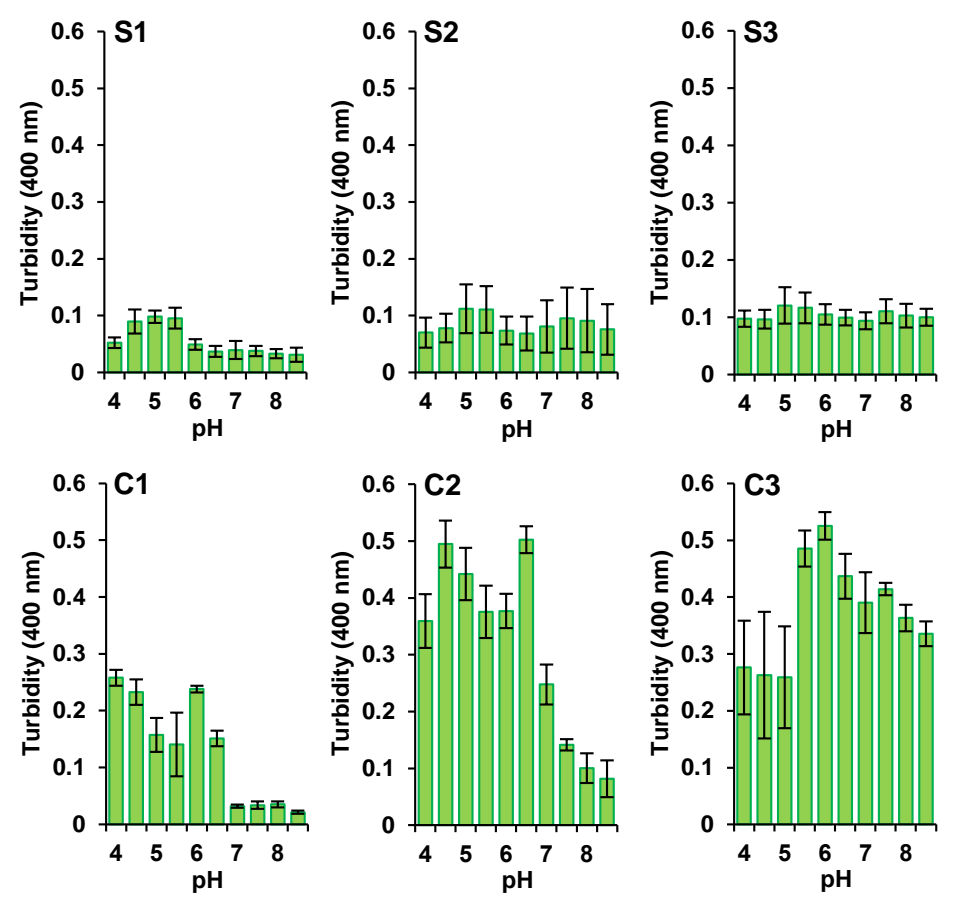

Figure S5. Evolution of turbidity of Sus-dextran (S1 to S3) and Cyc-dextran (C1to C3) solutions $(600 \mu \mathrm{g} / \mathrm{mL})$ at various $\mathrm{pH}$ values. 

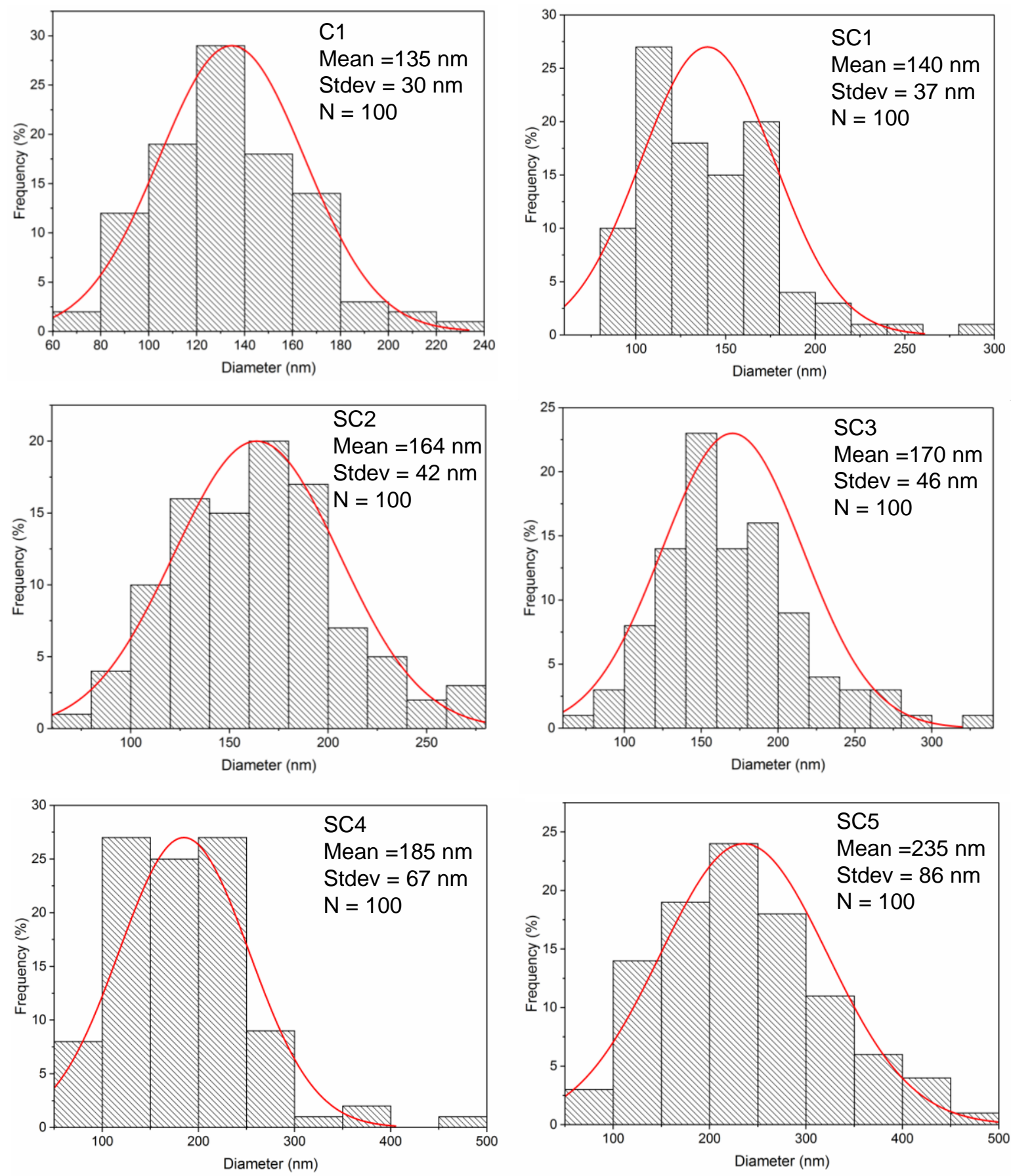

Figure S6. Distribution of diameters of dextran ester nanofibers with different degrees of substitution measured by SEM. 

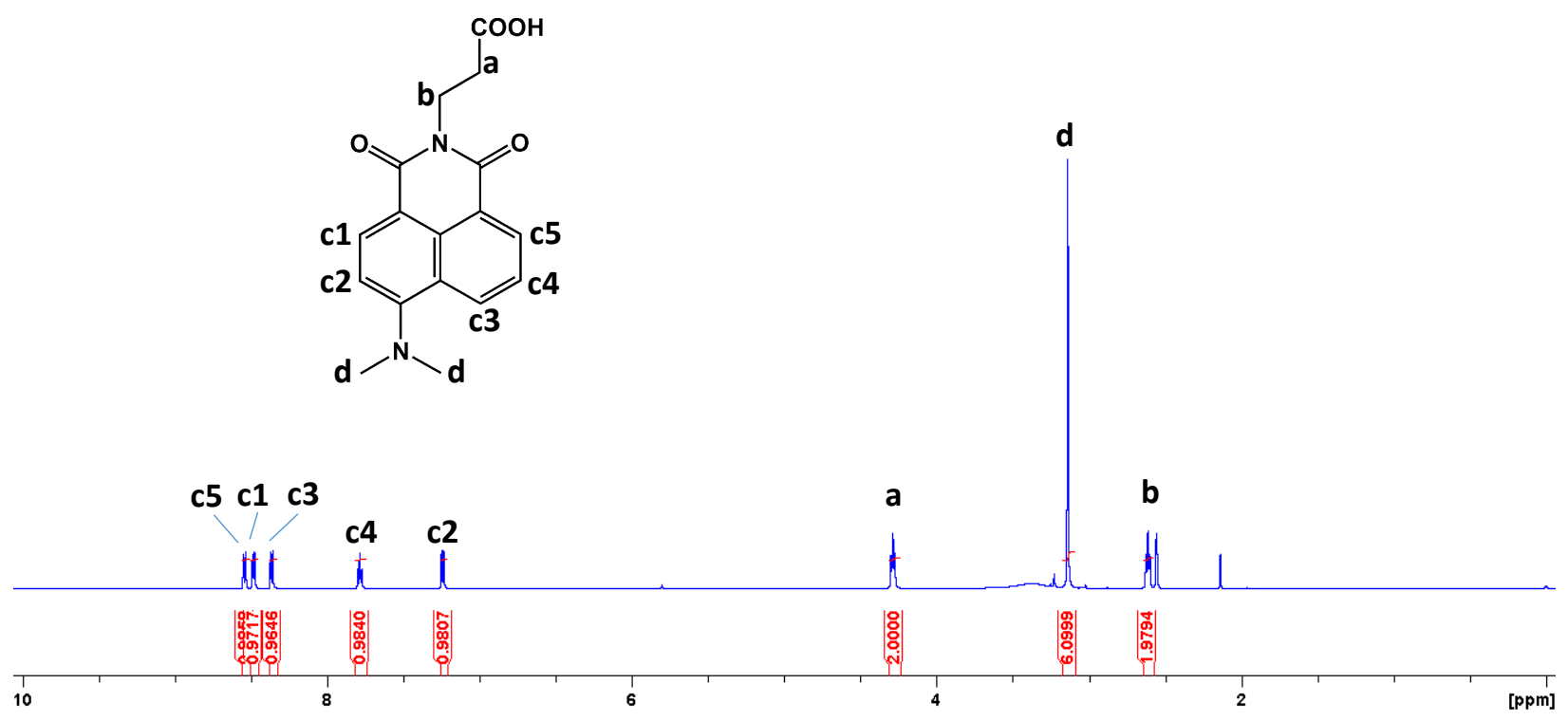

Figure S7. ${ }^{1} \mathrm{H}$ NMR spectrum of 4-dimethylamino-1,8-naphthalimide- $N$-propionic acid in DMSO-d6. 


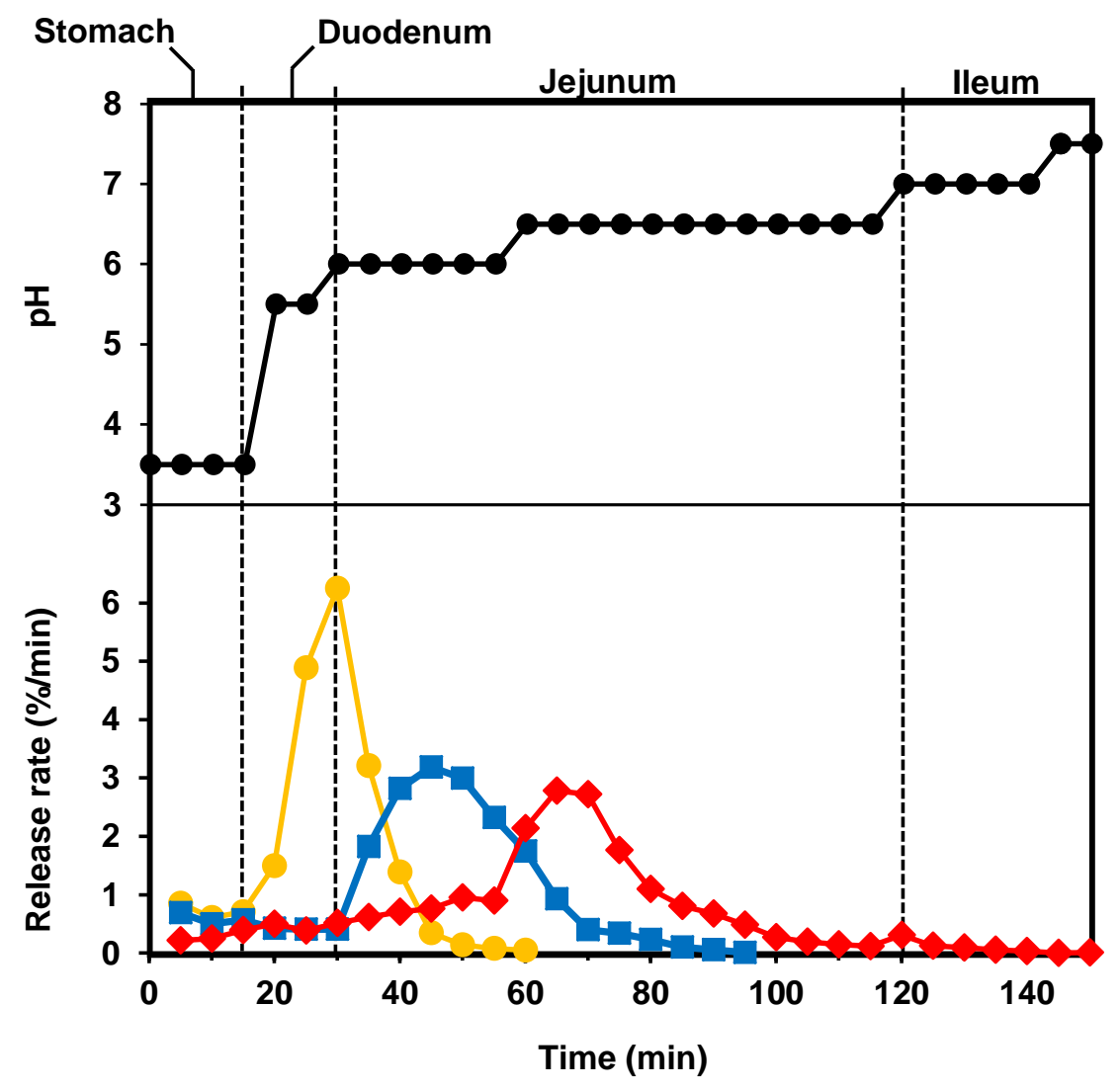

Figure S8. Release rate of three payloads ( Nap, $\square \mathrm{MB}$ and $\diamond \mathrm{RhB}$ ) from multilayered electrospun nanofibers in which transit time and $\mathrm{pH}$ values were simulated. 